Check for updates

Cite this: Chem. Sci., 2019, 10, 9548

๑ All publication charges for this article have been paid for by the Royal Society of Chemistry

Received 1st August 2019

Accepted 26th August 2019

DOI: $10.1039 /$ c9sc03832a

rsc.li/chemical-science

\section{Diastereoselective ring opening of fully-substituted cyclopropanes via intramolecular Friedel-Crafts alkylation $\uparrow$}

\author{
Veeranjaneyulu Lanke, Fa-Guang Zhang, (D) Alexander Kaushansky and Ilan Marek (D)*
}

We herein disclose a diastereoselective ring opening of non-donor-acceptor cyclopropanes via an intramolecular Friedel-Crafts alkylation en route to functionalized dihydronaphthalene scaffolds possessing quaternary carbon stereocentres. The transformation proceeds through a selective bond breaking at the most alkylated carbon centre with a pure retention of configuration. Mechanistic investigations and computational studies revealed that alkoxy functionality is the key for selective bond breaking leading to a complete retention of configuration.

Cyclopropenes have always been a valuable molecular scaffold in organic synthesis as they could selectively be functionalized into more densely substituted three-membered rings. ${ }^{1}$ In the case of nucleophilic addition on the strained double bond, the resulting cyclopropane can undergo selective ring opening ${ }^{2}$ producing highly functionalized cyclic, acyclic or heterocyclic building blocks that are essential for the synthesis of natural products and biological active compounds. ${ }^{3,4}$ Among all possible strategies for ring-opening of strained-rings, donoracceptor cyclopropanes ${ }^{5}$ have attracted a particular attention because of the simplicity, reliability, atom-economy and notable chemo-, regio-, and stereoselectivities of the reaction although the formation of acyclic quaternary stereocentre remains one challenging problem (Scheme 1a). ${ }^{6}$ In the context of selective ring-opening, and based on the catalytic Nazarov cyclization, ${ }^{7}$ the formal homo-Nazarov process (Scheme 1b), ${ }^{8}$ transforms an activated cyclopropane into a six-membered ring carbocycle. Despite the high reactivity of cyclopropanes, this formal homoNazarov reaction proceed efficiently only when additional activating groups are present either by (i) introducing a second electron-withdrawing group $\alpha$ - to the carbonyl group, (ii) introducing a heteroatom at the $\alpha^{\prime}$-position to the ketone or (iii) increasing the donor-acceptor properties of the cyclopropane core by using heteroatoms as donor partners in a $\gamma$-position (Scheme 1b). ${ }^{9}$ Mechanistically, the reaction usually involves cyclopropane ring-opening in the presence of a Lewis acid catalyst, followed by an intramolecular Friedel-Crafts alkylation. ${ }^{10}$ In these lines, Nishii and coworkers has utilized the

Schulich Faculty of Chemistry, Technion - Israel Institute of Technology, Technion City 3200009, Haifa, Israel. E-mail: chilanm@technion.ac.il

$\dagger$ Electronic supplementary information (ESI) available. CCDC 1888210 and 1937437. For ESI and crystallographic data in CIF or other electronic format see DOI: $10.1039 / \mathrm{c} 9 \mathrm{sc} 03832 \mathrm{a}$
homo-Nazarov strategy to synthesize $( \pm)$-cyclogalgravin and $(+)$-podophyllic aldehydes. ${ }^{10 d, e}$

To further validate the mechanism of the cyclization reaction, the same group has synthesized the two independent diastereoisomers ${ }^{10 a} \mathbf{1 a}$ and $\mathbf{1 b}$ and under the same experimental condition, both diastereoisomers provided the same product 2 . Although not a formal homo-Nazarov process, the trans stereochemistry between the two stereogenic centres supports a stepwise Friedel-Crafts type mechanism $\left(S_{N} 1\right)$ where the benzylic stereocentre epimerizes into the less sterically shielded stereoface (anti to the substituent in the $\beta$-position). As a consequence of this stepwise Friedel-Crafts type mechanism $\left(\mathrm{S}_{\mathrm{N}} 1\right)$, no example was reported for the formation of quaternary stereocentre as the two diastereoisomers should be formed in equivalent amount.

As one of the research areas of our group concern with the stereoselective preparation of quaternary stereocentres, we have reported the preparation of these latter ${ }^{11}$ by the in situ formation of donor-acceptor cyclopropanes. Those strategies relied on the combined diastereoselective carbometalation reactions of cyclopropenes $^{12}$ followed by reaction of the generated cyclopropyl metal species with ambiphilic electrophiles such as carbenoids, ${ }^{13}$ oxenoids ${ }^{14}$ or acylsilane ${ }^{15}$ promoting subsequent selective ring-opening reactions (Scheme 1c). In all of these above-mentioned transformations, the quaternary stereocentre generated during the carbometalation reaction was at no risk of epimerization except for the ring-expansion of 3 into cyclobutene (Scheme 1c). ${ }^{15 b}$ In this case, a complete preservation of the stereochemistry was observed during the $\mathrm{C}-\mathrm{C}$ bond migration. Although mechanistically not related, we were nevertheless intrigued by the discrepancy between this complete preservation of the stereochemistry during the ring-expansion of 3 into polysubstituted cyclobutenes (Scheme $1 \mathrm{c})^{15 b}$ with the $\mathrm{S}_{\mathrm{N}} 1$ character of the ring expansion of $\mathbf{1 a}$ and $\mathbf{1 b}$ (Scheme $1 \mathrm{~b}$ ). ${ }^{10 a}$ 

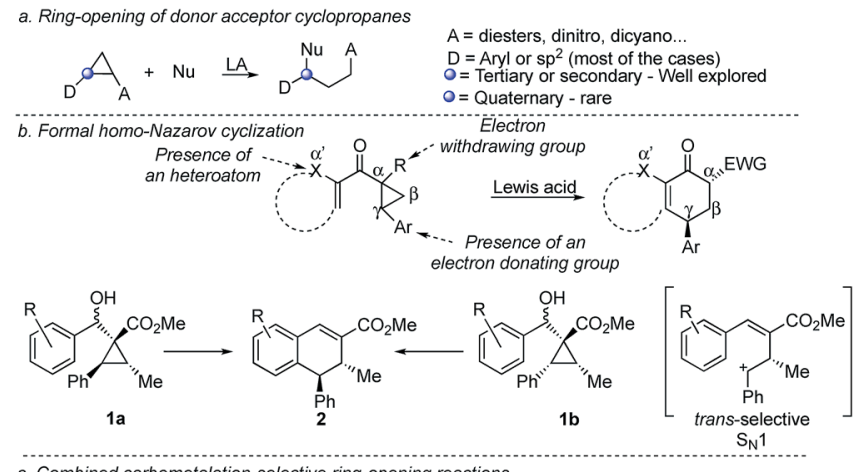

c. Combined carbometalation-selective ring-opening reactions
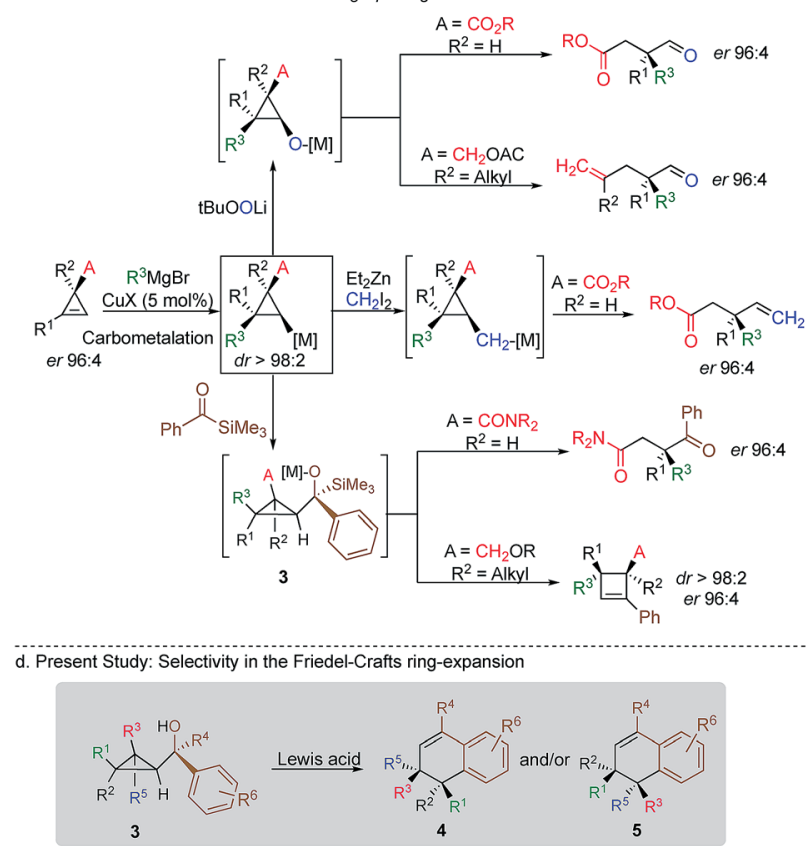

Scheme 1 Selectivity in the ring-opening of three-membered rings.

We were therefore wondering what would be the stereochemistry of the Lewis-acid catalysed Friedel-Crafts ring-expansion products of 3 possessing the previously unreported quaternary sterocentres (Scheme 1d). When our model substrate $3 \mathbf{a}\left(\mathrm{R}^{1}=\right.$ $\mathrm{Me}, \mathrm{R}^{2}=\mathrm{Bu}, \mathrm{R}^{3}=\mathrm{CH}_{2} \mathrm{OMe}, \mathrm{R}^{4}=\mathrm{SiMe}_{3}, \mathrm{R}^{5}=\mathrm{R}^{6}=\mathrm{H}$ ) was treated with $\mathrm{FeCl}_{3}(20 \mathrm{~mol} \%)$ as Lewis acid, the desired FriedelCrafts alkylation product (4a) was obtained in $50 \%$ or $58 \%$ yield at respectively $60{ }^{\circ} \mathrm{C}$ or room temperature along with intramolecular fragmented product 6a (Table 1, entries 1 and 2) but without any traces of the rearranged product 5a. Remarkably, $\mathbf{4 a}$ was obtained as a single diastereoisomer. Screening various different Lewis or Brønsted acids did not improve yield of $\mathbf{4 a}$ (Table 1, entries 3-7). When the reaction was performed at lower temperature, 4a could be isolated in $72 \%$ yield with a minimum amount of $\mathbf{6 a}$ (Table 1 , entry 8). After additional screening (see ESI $\dagger$ ), we were delighted to find two additional optimal conditions (Table 1, entries 9 and 10). In the first case, $\mathrm{FeCl}_{3}(20 \mathrm{~mol} \%)$ was combined with $\mathrm{AgSbF}_{6}$ as cocatalyst (40 mol\%) in toluene $(0.1 \mathrm{M})$ at $-15{ }^{\circ} \mathrm{C}$ to room temperature to provide the desired product in $76 \%$ yield. In the second case, the quantity of $\mathrm{FeCl}_{3}$ was increased to $40 \mathrm{~mol} \%$ without
Table 1 Optimization of reaction conditions ${ }^{a}$

\begin{tabular}{|c|c|c|c|c|}
\hline $\begin{array}{r}\text { Bu }{ }^{\prime}{ }_{\text {H }} \\
\text { 3a }\end{array}$ & $\begin{array}{l}{ }_{\text {. }} \mathrm{SiMe}_{3} \\
\mathrm{Ph} \quad \begin{array}{l}\text { Lewis } \\
\text { acid }\end{array} \\
\overrightarrow{\mathrm{Mec}}\end{array}$ & & $\mathrm{SiMe}_{3}$ & $\mathrm{OCH}_{2}{ }^{\mathrm{TMS}}$ \\
\hline Entry & Catalyst (mol\%) & Solvent & $T\left({ }^{\circ} \mathrm{C}\right) /$ time $(\mathrm{h})$ & $4 \mathbf{a} / 5 \mathbf{a} / 6 \mathbf{a}^{b}$ \\
\hline 1 & $\mathrm{FeCl}_{3}(20)$ & Toluene & $60 / 3$ & $50 / 0 / 12$ \\
\hline 2 & $\mathrm{FeCl}_{3}(20)$ & Toluene & $\mathrm{rt} / 3$ & $58 / 0 / 10$ \\
\hline 3 & $\mathrm{FeCl}_{2}(20)$ & Toluene & $\mathrm{rt} / 12$ & $0 / 0 / 0$ \\
\hline 4 & $\mathrm{Bi}(\mathrm{OTf})_{3}(20)$ & Toluene & $\mathrm{rt} / 12$ & $40 / 0 / 18$ \\
\hline 5 & $\mathrm{Cu}(\mathrm{OTf})_{2}(20)$ & Toluene & $\mathrm{rt} / 12$ & $22 / 0 / 8$ \\
\hline 6 & $\mathrm{BF}_{3} \cdot \mathrm{OEt}_{2}(20)$ & Toluene & $\mathrm{rt} / 4$ & $48 / 0 / 0$ \\
\hline 7 & $\mathrm{TsOH}(100)$ & Toluene & $\mathrm{rt} / 0.5$ & $32 / 0 / 11$ \\
\hline 8 & $\mathrm{FeCl}_{3}(20)$ & $\mathrm{CH}_{2} \mathrm{Cl}_{2}$ & -15 to $\mathrm{rt} / 3$ & $72 / 0 / 10$ \\
\hline $9^{c}$ & $\mathrm{FeCl}_{3}(20)$ & Toluene & -15 to $\mathrm{rt} / 3$ & $76^{d} / 0 / 7$ \\
\hline 10 & $\mathrm{FeCl}_{3}(40)$ & $\mathrm{CH}_{2} \mathrm{Cl}_{2}$ & -15 to $\mathrm{rt} / 3$ & $81^{d} / 0 / 9$ \\
\hline
\end{tabular}

${ }^{a}$ Condition: 3a $(0.3 \mathrm{mmol})$, solvent $(3 \mathrm{~mL}) .{ }^{b} \mathrm{NMR}$ yield using $p$ methoxy acetophenone as internal standard. ${ }^{c} \mathrm{AgSbF}_{6}(40 \mathrm{~mol} \%)$ used as an additive. ${ }^{d}$ Yield of isolated product after purification by column chromatography.

cocatalyst and the product $4 \mathbf{a}$ was isolated in $81 \%$ yield as single diastereoisomer without any detectable amount of 5a. Having in hand the best experimental conditions, we first briefly evaluated the role of the TMS group in the formation of $\mathbf{4}$ and subsequently explored the scope of the reaction by varying the nature of all substituents $\mathrm{R}^{1}$ to $\mathrm{R}^{5}$ on the cyclopropanes (Scheme 2). For the effect of the TMS group, four different substrates $\mathbf{3 a}-\mathbf{d}$ were prepared using our conventional strategy (see the ESI $\dagger$ ).

In contrast to $\mathbf{3 a}$, where the corresponding dihydronaphthalene 4a was obtained in good yield (Scheme 2), secondary alcohol $\mathbf{3 b}\left(\mathrm{R}^{4}=\mathrm{H}\right)$ led quantitatively to the product of fragmentation without any trace of $\mathbf{4 b}$ (Scheme 2). This result is in good agreement with previous studies underlining the need of either a donor-acceptor cyclopropane or a substrate possessing a benzylic stereocentre. ${ }^{12-15}$ On the other hand, benzylic tertiary alcohols $\left(\mathbf{3 c} \mathrm{R}^{4}=\mathrm{Me}\right.$ and $\left.\mathbf{3 d} \mathrm{R}^{4}=\mathrm{Ph}\right)$ provided the desired product $4 \mathbf{c}, \mathbf{4 d}$ in moderate yields along the fragmented products (Scheme 2, respectively). It should be noted again that in all these cases, the products $\mathbf{4 a}, \mathbf{4 c}$ and $\mathbf{4 d}$ were formed as a single diastereoisomer. These results suggest that the reaction doesn't proceed anymore through a stepwise Friedel-Crafts $\left(\mathrm{S}_{\mathrm{N}} 1\right)$ type mechanism as a mixture of two diastereoisomer would be expected at the quaternary carbon centre. To further check this mechanistic assumption, the nature of the substituents $\mathrm{R}^{1}$ and $\mathrm{R}^{2}$ were permuted and the opposite diastereoisomer at the quaternary carbon stereocentre was formed with a similar diastereoselectivity underlying that the reaction is stereospecific (Scheme 2a, compare 4a and 4e from 3a and 3e). Various products possessing differently substituted quaternary carbon stereocentres were prepared with similar efficiencies and yields (Scheme 2, 4f-h). Structural variation of the aromatic ring doesn't impede the reaction to proceed (Scheme 2, $\mathbf{4 i}, \mathbf{4 j}, \mathbf{4 n}$ ). Changing the coordinating group from methoxy (4a) to 


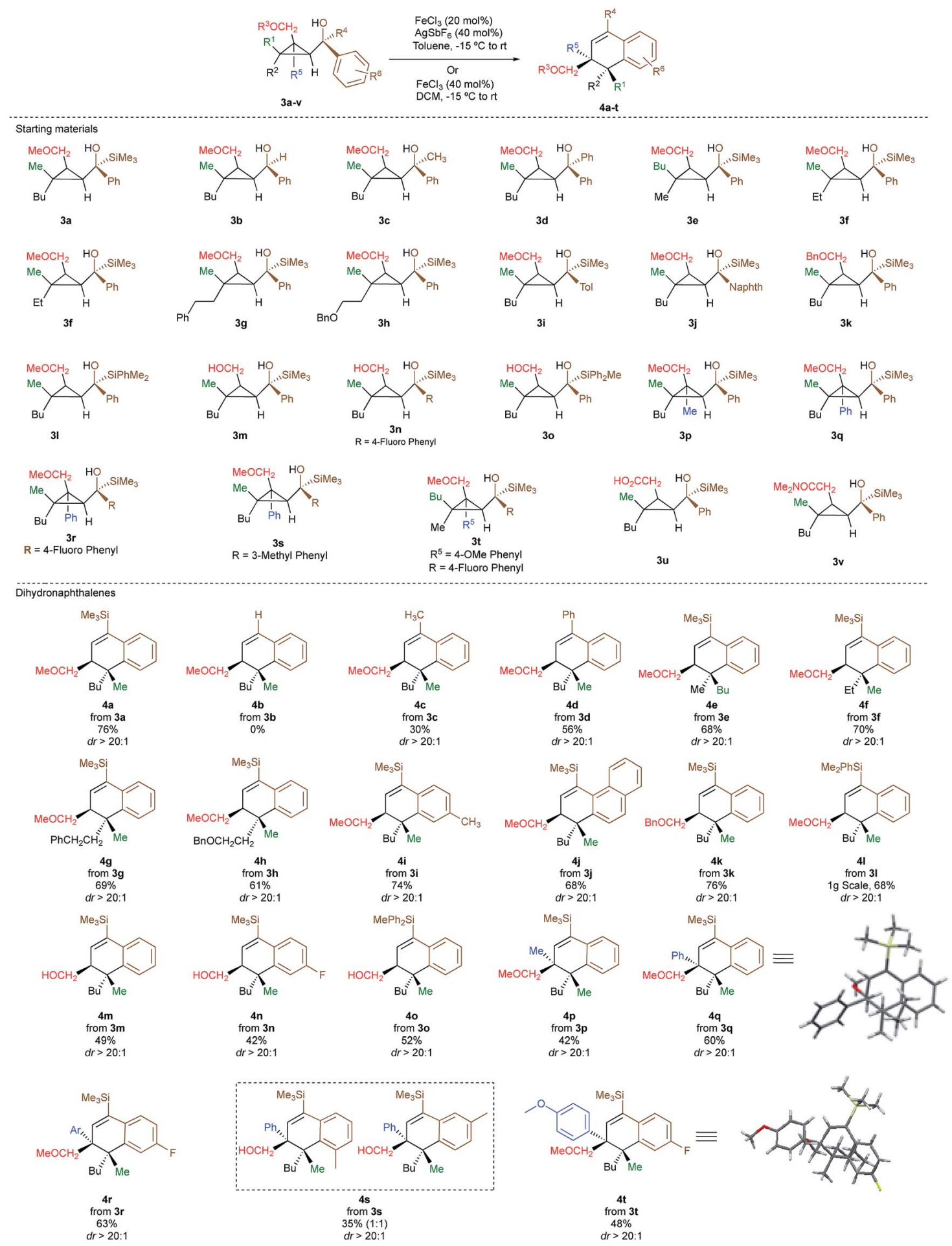

Scheme 2 Preparation of dihydronaphthalenes.

benzyloxy (4k) or changing TMS group (4a) to DMPS (41), didn't alter the transformation. The presence of a free alcohol seriously decreased the overall yield $(\mathbf{4 m}-\mathbf{4 o})$, whereas the presence of a carboxylic acid or amide as a coordinating group failed to furnish the expected products under all tested reaction conditions (Scheme 2, 3u, 3v). ${ }^{17}$ Finally, five additional interesting examples show that products possessing two quaternary carbon stereocentres can be prepared underlining the unique selectivity of the carbon-carbon bond cleavage in the process (Scheme 2, $\mathbf{4 p - 4 t )}$. The configuration of $\mathbf{4 p}$ was established by NMR studies (see ESI $\dagger$ ) and by X-ray crystallographic analysis for compounds $\mathbf{4 q}$ and $\mathbf{4 t}$ confirming that the rearrangement proceeds with a pure overall retention of configuration at the 

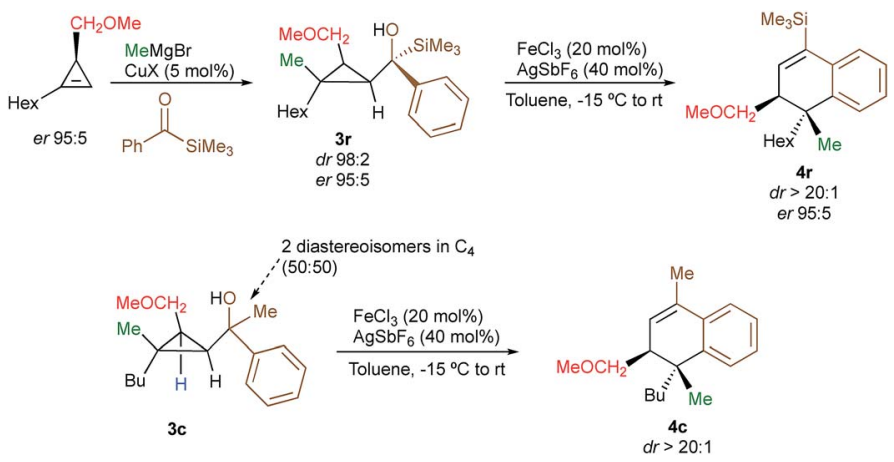

Scheme 3 Diastereo- and enantioselective preparation of dihydronaphthalene.

quaternary stereocentre. ${ }^{16}$ The configuration of all other products were assigned by analogy.

With a practical method to prepare dihydronaphthalenes possessing a quaternary and tertiary carbon stereocentres from simple cyclopropenes, substrate $3 \mathbf{w}\left(\mathrm{R}^{1}=\mathrm{Me}, \mathrm{R}^{2}=\mathrm{Hex}, \mathrm{R}^{3}=\right.$ $\mathrm{Me}, \mathrm{R}^{4}=\mathrm{SiMe}_{3}, \mathrm{R}^{5}=\mathrm{H}$ ) was readily synthesized from the corresponding cyclopropene with high enantioselectivity (er $95: 5$ ) through catalytic decomposition of diazo ester with 1-octyne. ${ }^{18}$ The copper-catalysed carbomagnesiation followed by addition of an acylsilane provide $3 \mathbf{w}$ as a single diastereoisomer with the same enantiomeric ratio than the starting material (Scheme 3, $\mathrm{dr}>98: 2$; er $95: 5$ ). The subsequent Lewis acid-catalysed selective ring-opening and rearrangement afforded dihydronaphthalene $\mathbf{4 w}$ as a single diastereoisomer without any loss in enantiomeric purity $(\mathrm{dr}>20: 1$, er $95: 5$, Scheme 3, see ESI $\dagger$ ) confirming that the reaction proceeds with a complete retention of configuration at the migratory carbon centre. To determine whether the migratory aptitude is independent of the stereochemistry at the benzylic stereocentre in $\mathrm{C}_{4}$, a mixture of the two diastereoisomers of $\mathbf{3 c}$ were prepared and subjected to our experimental conditions. Although lower yields were observed as discussed previously when $\mathrm{R}^{4}=\mathrm{Me}$, the rearranged product $4 c$ was generated with the same selectivity ( $\mathrm{dr}>20: 1$, Scheme 3) underlining that the rearrangement is unrelated to the stereochemistry at the benzylic alcohol.

Since the dihydronaphthalene or tetralin cores represent a common scaffold in many biologically active compounds, ${ }^{10,19}$ we could showcase the selective reduction of the double bond (formation of 7) and deprotection of TMS group (formation of $\mathbf{4 b}$, Scheme 4) with equal efficiency. It should be noted that the silicon moiety could be used for subsequent cross-coupling reaction $\mathbf{s}^{20}$ but also as a surrogate of a hydrogen, leading to the product $\mathbf{4 b}$ that was not accessible directly from $\mathbf{3 b}$ (Scheme 2). All attempts to transform $\mathbf{4 r}$ into tetralone by oxidation of the corresponding vinylsilane failed.
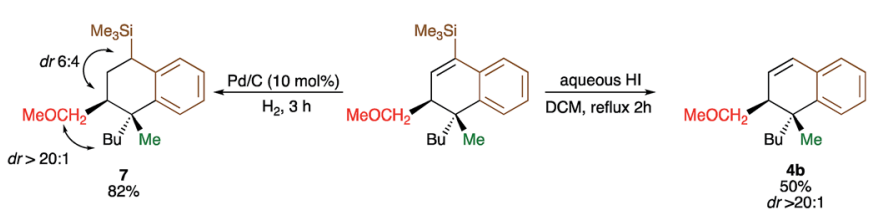

Scheme 4 Selective manipulation of dihydronaphthalene.
To shed additional light on the selectivity of the ringexpansion proceeding with a pure retention of configuration at the migratory carbon centre, we compared the behaviour of several starting materials (Schemes 2 and $5 \mathrm{a}$ ) in this Lewis acidcatalysed Friedel-Crafts rearrangement. In all cases, the C-C bond cleavage is exceptionally selective with a pure retention of configuration always leading either to the fragmentation at the most-substituted carbon centre or with a unique selectivity when two quaternary stereocentres are present in the cyclopropyl ring. Even when a benzylic centre is concerned $\left(\mathrm{R}^{5}=\mathrm{Ph}\right.$, formation of $\mathbf{4 q}$ ), the selectivity is unique and the migrating group is always the one that do not possess the alkoxyfunctionality. However, when the methoxy group is absent, the ring expansion still proceeds but without any selectivity (formation of $\mathbf{4 x}$ and $\mathbf{5 x}$ in a 2 to 1 ratio as inseparable mixture of products, Scheme $5 \mathrm{~b}$ ). Based on these control experiments, we can conclude that the selectivity of the ring-expansion is controlled by the presence of the alkoxy group allowing the Friedel-Crafts reaction to proceed stereospecifically. It should be added that the effect of the substituent $\mathrm{R}^{4}$ on the rearrangement (compare $\mathbf{4 a}$ to $\mathbf{4 d}$, Scheme 2), only $\boldsymbol{\alpha}$-hydroxysilane provides good yield of the rearranged products, suggesting that the silicon atom add an extra stabilization in the process.
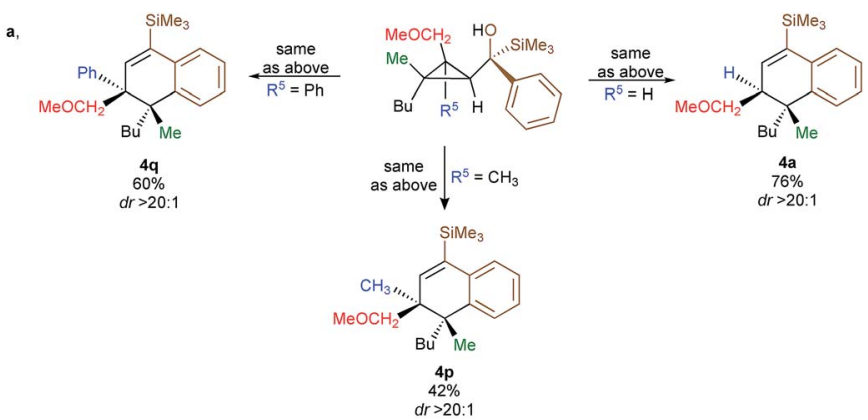

b,

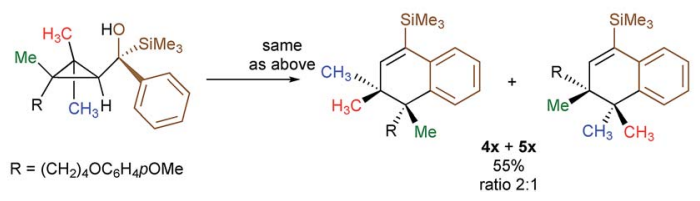

Scheme 5 Mechanistic insights. 


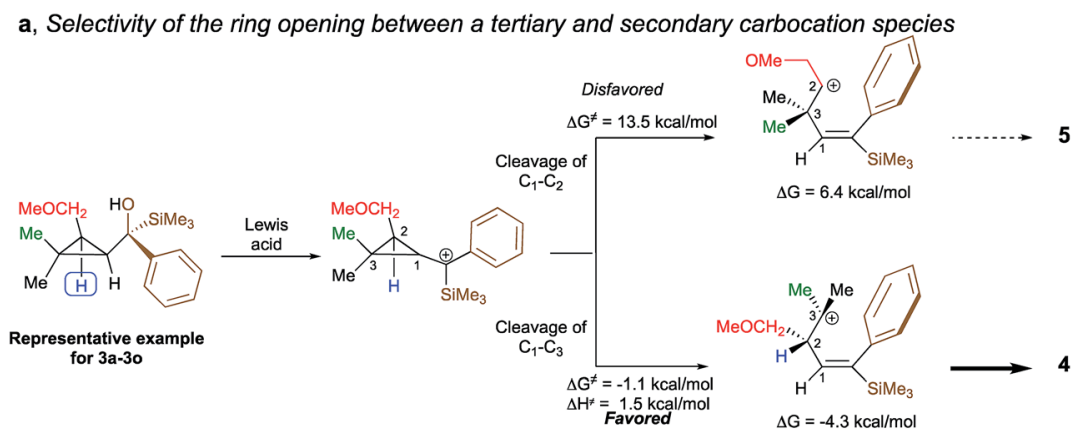

b, Selectivity of the ring opening between two tertiary carbocation species.

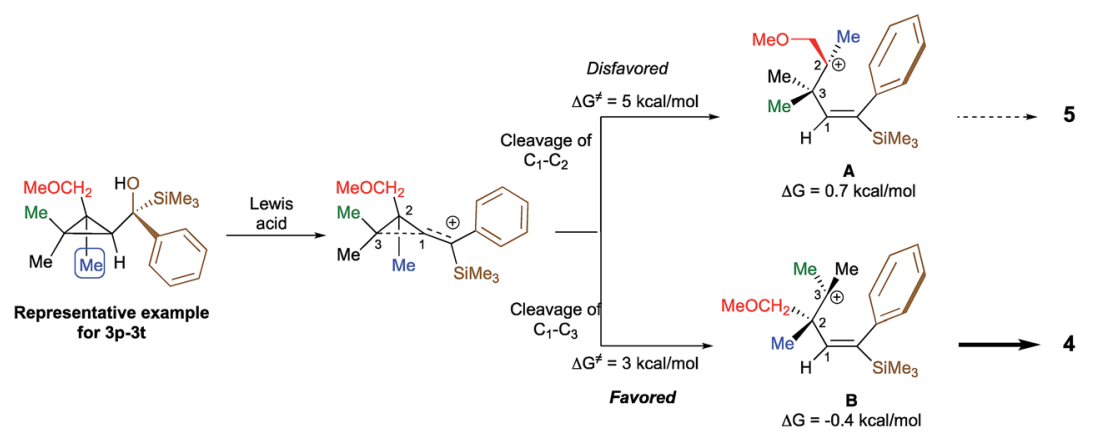

c, Isodesmic reaction illustrating the negative inductive effect of the MeO group in carbocation stability

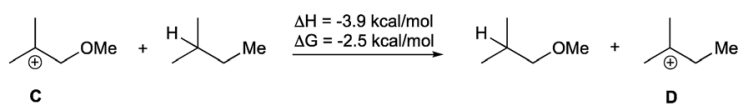

d, Stereospecificity resulting from restricted possible rotations

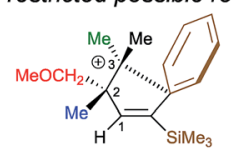

e, Overall mechanistic picture for the transformation of 3 into 4

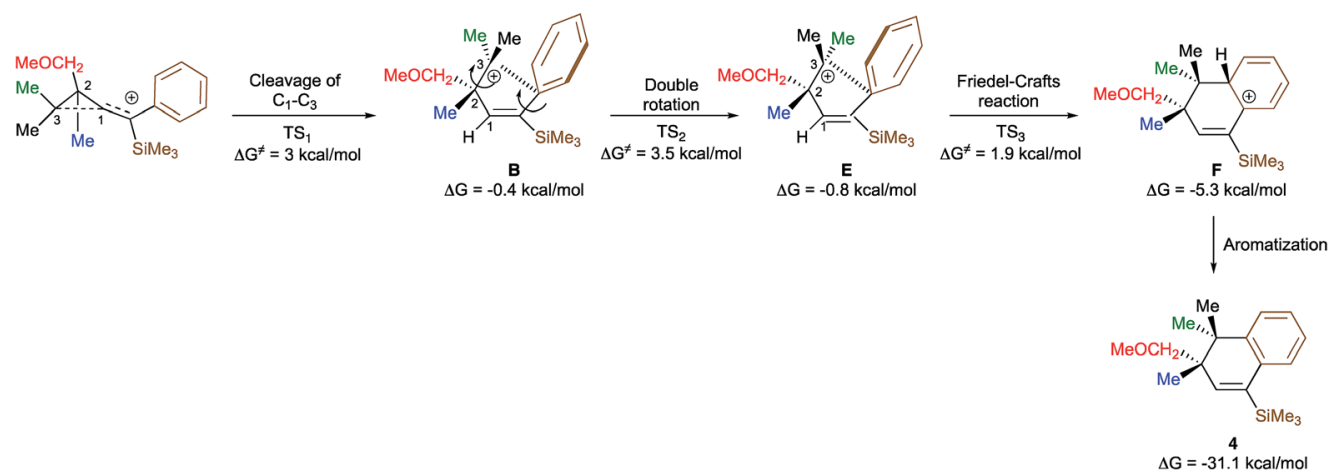

Scheme 6 Rationalization for the proposed mechanism.

\section{Computational studies}

To better understand the origin of the selectivity for the ringopening as well as the stereospecificity of the process, the reaction mechanism was investigated by density functional theory calculations $^{21}$ at $\mathrm{M} 062 \mathrm{X} / 6-311+\mathrm{g}(\mathrm{d}, \mathrm{p})$ level of theory in dichloromethane. The overall process is essentially exothermic with enthalpy and Gibbs free energy -31.1 and $-33.7 \mathrm{kcal} \mathrm{mol}^{-1}$ respectively (see ESI for all details $\dagger$ ). We first studied the selectivity of the ring-opening of the reaction and we found that the stability of the intermediate carbocation dictates the selectivity of the ring-opening. Although the selectivity was obvious for the 
transformation of 3a to 30 into $4 \mathbf{a}$ to $4 \mathbf{0}$, where the formation of a tertiary carbocation is preferred over the formation of a secondary carbocation (Scheme 6a), it became much less evident when two tertiary carbocations (3p-3t into $\mathbf{4 p - 4 t )}$ are concerned. Although our initial hypothesis was that an anchimeric effect was controlling the selectivity of the ring-opening as well as the stereospecificity, calculations show that the negative inductive effect of the methoxy group is the key-controlling element by slightly destabilizing the formation of the carbocation $\mathbf{A}$, generated through the cleavage of the $\mathrm{C}_{1}-\mathrm{C}_{2}$ bond, as compared to the formation of the carbocation $\mathbf{B}$ that would be generated by the cleavage of the $\mathrm{C}_{1}-\mathrm{C}_{3}$ bond (Scheme $6 \mathrm{~b}$ ). Full details of the results of the calculations are given in the $\mathrm{ESI}^{\dagger}$ material including the non-productive approach through anchimeric effect, where the 4-membered oxonium could not undergo the subsequent Friedel-Crafts cyclization. To corroborate this hypothesis, the isodesmic reaction represented in Scheme $6 \mathrm{c}$ has been calculated and indeed shows that carbocation $\mathbf{C}$ is less stabilized than carbocation $\mathbf{D}$. If the methoxy group is not present as described in Scheme 5d, two isomers are formed and the final ratio depends on the stability of the carbocation intermediates.

Having now a good understanding on the selectivity of the ringopening, we then focus our attention to the stereospecificity of the reaction that was particularly puzzling in a process proceeding through carbocationic intermediates. Calculations shows that for the carbocation $\mathbf{B}$ to epimerize, a rotation around the $\mathrm{C}_{2}-\mathrm{C}_{3}$ bond has to occur. However, the system is geometrically blocked by the proximity of the aromatic ring $\left(d\left[\mathrm{C}^{3}-\mathrm{C}^{\mathrm{ipso}}\right]=2.86 \mathrm{~A}\right)$ impeding all epimerization (Scheme $6 \mathrm{~d}$ ). One could also consider that the $\mathrm{C}_{1}-\mathrm{C}_{2}$ rotation precedes the $\mathrm{C}_{2}-\mathrm{C}_{3}$ rotation but is much higher in energy $\left(\Delta G^{\#}=8.6 \mathrm{kcal} \mathrm{mol}^{-1}\right)$ than the Friedel-Crafts reaction described in Scheme 6e. Interestingly, the aromatization step (F into 4 ) is exergonic $\left(\Delta G=-25.9 \mathrm{kcal} \mathrm{mol}^{-1}\right)$ and is almost barrierless.

The overall picture of the reaction mechanism is then described in Scheme 6e where product $\mathbf{4}$ is selectively formed from the corresponding cyclopropane $\mathbf{3}$ by combining the selective ring-opening reaction controlled by the inductive effect of the alkoxy functionality and the stereospecific cyclization controlled by a restricted conformation of the carbocation.

\section{Conclusions}

In conclusion, a protocol for the diastereoselective preparation of functionalized dihydronaphthalene backbones, useful precursor of diterpenoids, was reported from easily accessible cyclopropanes in three catalytic steps from commercially available alkynes. The versatility of the transformation was illustrated by the complete selectivity of the ring-opening and by the stereospecificity during the migration. Mechanistic control experiments and computational studies reveal the key inductive effect of the alkoxy functionality in the selectivity of the carboncarbon bond cleavage and the $\pi$-stabilization of the carbocationic intermediates leading to an overall stereospecific process.

\section{Conflicts of interest}

There are no conflicts to declare.

\section{Acknowledgements}

This project has received funding from the European Union's Horizon 2020 Research and Innovation Program under grant agreement 786976-ERC and by the Ministry of Science and Technology (grant No. 330/17).

\section{Notes and references}

1 (a) L. Dian and I. Marek, Chem. Rev., 2018, 118, 8415; (b) C. Ebner and E. M. Carreira, Chem. Rev., 2017, 117, 11651; (c) X. Liu and J. M. Fox, J. Am. Chem. Soc., 2006, 128, 5600; (d) V. Tarwade, X. Liu, N. Yan and J. M. Fox, J. Am. Chem. Soc., 2009, 131, 5382; (e) M. L. Deem, Synthesis, 1972, 675; (f) A. B. Charette and A. Beauchemin, Org. React., 2001, 58, 1; $(g)$ M. Rubin, M. Rubina and V. Gevorgyan, Chem. Rev., 2007, 107, 3117; (h) M. Rubin, M. Rubina and V. Gevorgyan, Synthesis, 2006, 8, 1221; (i) M. Rubina and V. Gevorgyan, Tetrahedron, 2004, 60, 3129.

2 (a) I. Marek, A. Masarwa, P.-O. Delaye and M. Leibeling, Angew. Chem., Int. Ed., 2015, 54, 414; (b) B. Rybtchinski and D. Milstein, Angew. Chem., Int. Ed., 1999, 38, 870; (c) M. E. Van Der Boom and D. Milstein, Chem. Rev., 2003, 103, 1759; (d) C.-H. Jun, Chem. Soc. Rev., 2004, 33, 610; (e) Y. J. Park, J.-W. Park and C.-H. Jun, Acc. Chem. Res., 2008, 41, 222; (f) M. Murakami and T. Matsuda, Chem. Commun., 2011, 47, 1100; ( $g$ ) K. Ruhland, Eur. J. Org. Chem., 2012, 2683. 3 (a) S. Danishefsky, Acc. Chem. Res., 1979, 12, 66; (b) O. G. Kulinkovich, Russ. Chem. Rev., 1993, 62, 839; (c) H.-U. Reissig and R. Zimmer, Chem. Rev., 2003, 103, 1151; (d) L. A. Wessjohann, W. Brandt and T. Thiemann, Chem. Rev., 2003, 103, 1625; (e) C. A. Carson and M. A. Kerr, Chem. Soc. Rev., 2009, 38, 3051; (f) W. A. Donaldson, Tetrahedron, 2001, 57, 8589; $(g)$ C. A. Carson and M. A. Kerr, Chem. Soc. Rev., 2009, 38, 3051; (h) A. de Meijere, Cyclopropanes, Transformations, Houben-Weyl Methods of Organic Chemistry, Thieme, Stuttgart, Germany, 1997, vol. E17c; (i) Topics in Current Chemistry, ed. A. de Meijere, Springer, Berlin, 2000, vol. 207, DOI: 10.1007/3540-48255-5.

4 (a) P. Tang and Y. Qin, Synthesis, 2012, 44, 2969; (b) D.-H. Zhang, X.-Y. Tang and M. Shi, Acc. Chem. Res., 2014, 47, 913; (c) D. Y.-K. Chen, R. H. Pouwer and J.-A. Richard, Chem. Soc. Rev., 2012, 41, 4631.

5 Latest reviews on functionalization of donor-acceptor cyclopropane: (a) S. Liao, X. Sun and Y. Tang, Acc. Chem. Res., 2014, 47, 2260; (b) T. F. Schneider, J. Kaschel and D. B. Werz, Angew. Chem., Int. Ed., 2014, 53, 5504; (c) M. A. Cavitt, L. H. Phun and S. France, Chem. Soc. Rev., 2014, 43, 804; (d) K. L. Ivanov, E. V. Villemson, E. M. Budynina, O. A. Ivanova, I. V. Trushkov and M. Y. Melnikov, Chem.-Eur. J., 2015, 21, 4975; (e) A. K. Pandey, A. Ghosh and P. Banerjee, Isr. J. Chem., 2016, 56, 512; $(f)$ S. Racine, J. Vuilleumier and J. Waser, Isr. J. Chem., 2016, 56, 566; (g) E. M. Budynina, K. L. Ivanov, I. D. Sorokin and M. Y. Melnikov, Synthesis, 2017, 49, 3035. 
6 Selected examples of donor-acceptor cyclopropane reactions: (a) Y.-Y. Zhou, L.-J. Wang, J. Li, X.-L. Sun and Y. Tang, J. Am. Chem. Soc., 2012, 134, 9066; (b) J. Kaschel, T. F. Schneider, D. Kratzert, D. Stalke and D. B. Werz, Angew. Chem., Int. Ed., 2012, 51, 11153; (c) F. de Nanteuil, E. Serrano, D. Perrotta and J. Waser, J. Am. Chem. Soc., 2014, 136, 6239; (d) Q.-K. Kang, L. Wang, Q.-J. Liu, J.-F. Li and Y. Tang, J. Am. Chem. Soc., 2015, 137, 14594; (e) T. Kaicharla, T. Roy, M. Thangaraj, R. G. Gonnade and A. T. Biju, Angew. Chem., Int. Ed., 2016, 55, 10061; $(f)$ A. U. Augustin, M. Sensse, P. G. Jones and D. B. Werz, Angew. Chem., Int. Ed., 2017, 56, 14293; $(g)$ A. Lücht, L. J. Patalag, A. U. Augustin, P. G. Jones and D. B. Werz, Angew. Chem., Int. Ed., 2017, 56, 10587; (h) R. A. Novikov, D. D. Borisov, A. V. Tarasova, Y. V. Tkachev and Y. V. Tomilov, Angew. Chem., Int. Ed., 2018, 130, 10450; (i) A. Ortega, R. Manzano, U. Uria, L. Carrillo, E. Reyes, T. Tejero, P. Merino and J. L. Vicario, Angew. Chem., Int. $E d ., \quad 2018,57,8225$; (j) A. Reding, P. G. Jones and D. B. Werz, Org. Lett., 2018, 20, 7266.

7 (a) I. N. Nazarov and I. I. Zaretskaya, Izv. Akad. Nauk SSSR, Ser. Khim., 1941, 211. For reviews, see: (b) K. L. Habermas, S. E. Denmark and T. K. Jones, Org. React., 1994, 45, 1; (c) M. A. Tius, Eur. J. Org. Chem., 2005, 2193; (d) A. J. Frontier and C. Collison, Tetrahedron, 2005, 61, 7577; (e) T. N. Grant, C. J. Rieder and F. G. West, Chem. Commun., 2009, 5676; $(f)$ W. Nakanishi and F. G. West, Curr. Opin. Drug Discovery Dev., 2009, 12, 732; $(g)$ T. Vaidya, R. Eisenberg and A. J. Frontier, ChemCatChem, 2011, 3, 1531. 8 (a) W. S. Murphy and S. Wattanasin, Tetrahedron Lett., 1980, 21, 1887; (b) W. S. Murphy and S. Wattanasin, J. Chem. Soc., Perkin Trans. 1, 1981, 2920; (c) W. S. Murphy and S. Wattanasin, J. Chem. Soc., Perkin Trans. 1, 1982, 271; (d) W. S. Murphy and S. Wattanasin, J. Chem. Soc., Perkin Trans. 1, 1982, 1029; (e) O. Tsuge, S. Kanemasa, T. Otsuka and T. Suzuki, Bull. Chem. Soc. Jpn., 1988, 61, 2897; (f) L. Greiner-Bechert, T. Sprang and H.-H. Otto, Monatsh. Chem., 2005, 136, 635; $(g)$ V. K. Yadav and N. V. Kumar, Chem. Commun., 2008, 3774.

9 (a) M. C. Martin, R. Shenje and S. France, Isr. J. Chem., 2016, 56, 499; (b) C. W. Williams, R. Shenje and S. France, J. Org. Chem., 2016, 81, 8253; (c) M. J. Sandridge and S. France, Org. Lett., 2016, 18, 4218; (d) F. De Simone, T. Saget, F. Benfatti, S. Almeida and J. Waser, Chem.-Eur. J., 2011, 17, 14527; (e) F. De Simone, J. Andres, R. Torosantucci and J. Waser, Org. Lett., 2009, 11, 1023.

10 (a) W. Wu, Z. Lin and H. Jiang, Org. Biomol. Chem., 2018, 16, 7315; (b) K. Sasazawa, S. Takada, T. Yubune, N. Takaki, R. Ota and Y. Nishii, Chem. Lett., 2017, 46, 524; (c) S. Takada, N. Takaki, K. Yamada and Y. Nishii, Org. Biomol. Chem., 2017, 15, 2443; (d) E. Yoshida, K. Nishida, K. Toriyabe, R. Taguchi, J. Motoyoshiya and Y. Nishii, Chem. Lett., 2010, 39, 194; (e) J. Ito, D. Sakuma and Y. Nishii, Chem. Lett., 2015, 44, 297; (f) D. Sakuma, J. Ito, R. Sakai, R. Taguchi and Y. Nishii, Chem. Lett., 2014, 43, 610. 11 (a) G. Sklute, D. Amsallem, A. Shibli, J. P. Varghese and I. Marek, J. Am. Chem. Soc., 2003, 125, 11776; (b) G. Sklute and I. Marek, J. Am. Chem. Soc., 2006, 128, 4642; (c) G. Sklute and I. Marek, Chem. Commun., 2007, 1683; (d) G. Kolodney, G. Sklute, S. Perrone, P. Knochel and I. Marek, Angew. Chem., Int. Ed., 2007, 46, 9291; (e) B. Dutta, N. Gilboa and I. Marek, J. Am. Chem. Soc., 2010, 132, 5588; $f f$ T. Mejuch, B. Dutta, M. Botoshansky and I. Marek, Org. Biomol. Chem., 2011, 10, 5803; $(g)$ Y. Minko, M. Pasco, M. Botoshansky and I. Marek, Nature, 2012, 490, 522; (h) I. Marek, Y. Minko, M. Pasco, T. Mejuch, N. Gilboa, H. Chechik and J. P. Das, J. Am. Chem. Soc., 2014, 136, 2682.

12 (a) I. Marek, S. Simaan and A. Masarwa, Angew. Chem., Int. $E d ., 2007,46,7364$; (b) D. Didier, P.-O. Delaye, M. Simaan, B. Island, G. Eppe, H. Eijsberg, A. Kleiner, P. Knochel and I. Marek, Chem.-Eur. J., 2014, 20, 1038; (c) D. S. Müller and I. Marek, J. Am. Chem. Soc., 2015, 137, 15414; (d) D. S. Müller and I. Marek, Chem. Soc. Rev., 2016, 45, 4552; (e) M. Preshel-Zlatsin, F.-G. Zhang, G. Eppe and I. Marek, Synthesis, 2016, 48, 3279; (f) L. Dian, D. S. Muller and I. Marek, Angew. Chem., Int. Ed., 2017, 56, 6783; $(g)$ L. Dian and I. Marek, Angew. Chem., Int. Ed., 2018, 57, 3682; (h) H. Sommer and I. Marek, Chem. Sci., 2018, 9, 6503; (i) J. Bruffaerts, D. Pierrot and I. Marek, Nat. Chem., 2018, 10, 1164.

13 S. R. Roy, D. Didier, A. Kleiner and I. Marek, Chem. Sci., 2016, 7, 5989.

14 (a) M. Simaan, P.-O. Delaye, M. Shi and I. Marek, Angew. Chem., Int. Ed., 2015, 54, 12345; (b) M. Simaan and I. Marek, Angew. Chem., Int. Ed., 2018, 57, 1543.

15 (a) F. G. Zhang, G. Eppe and I. Marek, Angew. Chem., Int. Ed., 2016, 55, 714; (b) F.-G. Zhang and I. Marek, J. Am. Chem. Soc., 2017, 139, 8364; (c) C. Tugny, F. Zhang and I. Marek, Chem.Eur. J., 2018, 25, 205.

16 Crystallographic data have been deposited with the Cambridge Crystallographic Data Centre, accession number 4q: 1888210 and 4t: $1937437 . \dagger$

17 Although the focus of this research was on bond breaking and bond making even at quaternary centre possessing aliphatic groups with non-donor substituents (the most challenging substrates), a remark by a reviewer led us also to consider the stereochemical outcome of a more donoracceptor substrate 3 with a benzylic stereocenter (Scheme 1 d with $\mathrm{R}^{1}=\mathrm{Bu}, \mathrm{R}^{2}=\mathrm{H}, \mathrm{R}^{3}=\mathrm{Me}, \mathrm{R}^{4}=\mathrm{SiMe}^{3}, \mathrm{R}^{5}=\mathrm{Ph}$ and $\mathrm{R}^{6}=\mathrm{H}$ ). In this case, the product 5 was obtained with a diastereoisomer ratio of $95: 05$ indicating that even in this case, the stereochemistry is preserved.

18 Y. Lou, M. Horikawa, R. A. Kloster, N. A. Hawryluk and E. J. Corey, J. Am. Chem. Soc., 2004, 126, 8916.

19 (a) J. D. Sellars and P. G. Steel, Eur. J. Org. Chem., 2007, 3815; (b) P. Finkbeiner, K. Murai, M. Röpke and R. Sarpong, J. Am. Chem. Soc., 2017, 139, 11349.

20 A. Reding, P. G. Jones and D. B. Werz, Angew. Chem., Int. Ed., 2018, 57, 10610.

21 (a) R. G. Parr and W. Yang, Density Functional Theory of Atoms and Molecules, Oxford University Press, Oxford, 1994; $(b)$ W. Koch and M. C. Holthausen, A Chemist's Guide to Density Functional Theory, Wiley-VCH, Weinheim, 2001. 